\title{
The Expression of VEGF-C and It's Receptor VEGFR-3 Correlates with Lymph Node Metastasis in Gastric Cancer
}

\author{
Chun Yang1,2, Zhaoda Zhang ${ }^{2 *}$ \\ ${ }^{1}$ Department of Gastrointestinal Surgery, Sichuan Academy of Medical Sciences and Sichuan Provincial \\ People's Hospital, Chengdu, China \\ ${ }^{2}$ West China Medical School, West China Hospital, Sichuan University, Chengdu, China \\ Email: yang111chun@163.com
}

Received 10 September 2014; revised 23 October 2014; accepted 11 November 2014

Copyright (C) 2014 by authors and Scientific Research Publishing Inc.

This work is licensed under the Creative Commons Attribution International License (CC BY). http://creativecommons.org/licenses/by/4.0/

(c) (i) Open Access

\section{Abstract}

Background: Regional lymph node invasion and metastasis may happen early during the progression of gastric cancer. The lymphadenectomy is still the key method to treat lymph nodemetastasis. In the recent years, scientists have found some growth factors and receptors that can promote angiogenesis which also play an important role in adjusting the formation of the new lymph vessel, and lymphangiogenesis may play a key role in the process of lymph node metastasis. Objectives: This study aims to explore the correlation between the expression of vascular endothelial growth factor-C (VEGF-C), vascular endothelial growth factor receptor 3 (VEGFR-3) and lymph node metastasis (LNM), and its impact on prognosis of patients with gastric cancer. Methods: The samples were collected from gastric cancer database of Sichuan Provincial People's Hospital from 2005 to 2007, which were registered and followed up. The samples were divided into two groups according to situation whether there is lymph node metastasis, which is lymph node metastasis $N(+)$ and without lymph node metastasis $\mathrm{N}(-)$. The expression of VEGF-C, VEGFR-3 and CD34 were measured by immuno histochemistry staining with monoclonal antibody (anti-VEGF-C, anti-VEGFR-3, and anti-CD34). Kaplan-meier, logistic and Cox regression was performed to explore their impact on the prognosis of patients with gastric cancer. Results: In total 186 cases were collected, 96 cases in $\mathrm{N}(+)$ group and 90 cases in $\mathrm{N}(-)$ group. The percentage of VEGF-C expression is $54.83 \%$ $(102 / 186)$ in all groups, $73.9 \%(71 / 96)$ in $N(+)$ group, and $34.44 \%(31 / 90)$ in $N(-)$ group $(p=$ 0.001). The percentage of VEGFR-3 expression is 33.33\% (62/186) in all groups, 44.78\% (43/96) in $N(+)$ group, and $21.11 \%(19 / 90)$ in $N(-)$ group $(p=0.001)$. There are no statistical differences in microvessel density (MVD) between $N(-)$ and $N(+)$ group. The average lymphatic vessel density (LVD) was significant different between $N(+)$ and $N(-)$ group $(26.23 \pm 8.2$ and $18.46 \pm 7.4, t=$ $-2.427, p=0.016)$. The five-year overall survival rate of $N(+)$ group is $31 \%$ and the $N(-)$ group is

"Corresponding author.

How to cite this paper: Yang, C. and Zhang, Z.D. (2014) The Expression of VEGF-C and It's Receptor VEGFR-3 Correlates with Lymph Node Metastasis in Gastric Cancer. Open Journal of Gastroenterology, 4, 357-377. 
$66 \%$; there are statistical differences between the two groups $(\log \operatorname{rank}=27.15, p=0.001)$. The five-year overall survival rates of VEGF-C positive group and VEGF-C negative group are $36 \%$ and $59 \%$, with the statistical differences ( $\log$ rank $=27.15, p=0.001)$. And the five-year overall survival rates of VEGFR-3 positive group and VEGFR-3 negative group are $31 \%$ and $43 \%$, also with the statistical differences (Log rank $=5.241, p=0.041)$. Conclusions: The expressions of VEGF-C, VEGFR-3 in cell plasma of gastric cancer tissue not only correlate with lymphatic vessel density and lymph node metastasis (LNM), but also are important factors which impact prognosis of gastric cancer patients.

\title{
Keywords
}

\author{
Gastric Neoplasms, Vascular Endothelial Growth Factor-C, Vascular Endothelial Growth Factor \\ Receptor 3, Lymphangiogenesis, Lymphnode Metastasis
}

\section{Introduction}

Gastric cancer is one of the most common malignant tumors in the developing countries, whose incidence ranks the second place, only after lung cancer in the world [1]. Every year, there are about 952,000 new cases of gastric cancer and 723,000 cases died of it around the world [2]. Gastric cancer is the second most common malignant tumor in our country and its death rate takes the third place among all kinds of malignant tumors [3]. Even though the incidence rate has been in a downtrend in big and middle cities in the recent years with the progress of medical healthcare, the death rate still ranks high that gravely threatens the life and health of the citizens as one of the malignant tumors [3]. In addition, the incidence rate shows a younger trend, mainly ranging from 45 to 60 years old; the ratio of men to women is 2:1, which severely put people's life and health at risk [3].

In the process of gastric cancer, the most common metastasis mode is lymph node metastasis. Epidemiological statistical analysis found that even in early gastric cancer patients, the lymph node metastasis rate can reach about $10 \%-15 \%$. The scope and number of the lymph node metastasis decide the scope of lymphadenectomy in gastric cancer operations and directly affect the postoperative prognosis of the gastric cancer patients. In the recent years, with the non-stop development of research related to molecular biology, scientists have found some growth factors and receptors that can promote angiogenesis which also play an important role in adjusting the formation of the new lymph vessel and lymphangiogenesis may play a key role in the process of lymph node metastasis after the malignant progression [4]-[6]. The role of vascular endothelial growth factor-C (VEGF-C) and vascular endothelial growth factor receptor 3 (VEGFR-3) in malignant tumors is a hot field of cancer research. VEGF-C plays a key role in angiogenesis, lymphangiogenesis and endothelial cell growth and survival, and can also affect the permeability of blood vessels [7]. VEGFR-3, as the specific receptor for VEGF-C, is mainly expressed and restricted to the lymphatic endothelium, which is important in the development of lymphatic vessels and metastasis [8].

Current with the analysis of the expression of VEGF-C in the gastric cancer tissue and VEGFR-3 of the tumor edge and the correlation with lymph node metastasis, this study will explore its relationship with the formation of the new lymph vessel and tumor lymph node metastasis in order to analyze its impact on the prognosis of gastric cancer and preliminarily discuss the application value of the new lymph vessel targeted biological therapy.

\section{Materials and Methods}

\subsection{Major Reagents}

- Monoclonal antibody CD34: purchased from NEOMAKER, America;

- Monoclonal antibody VEGF-C: purchased from NEOMAKER, America;

- Monoclonal antibody VEGFR-3: purchased from NEOMAKER, America;

- Coomassie brilliant blue solution: purchased from LAB VISION, America

- $10 \%$ neutral formalin: formalin liquid, $10 \mathrm{ml} \& 0.01 \mathrm{~mol} / \mathrm{L} \mathrm{PBS}, 90 \mathrm{ml}$; 
- $0.01 \mathrm{~mol} / \mathrm{L}$ phosphate buffer saline (PBS) solution;

- Antigen retrieval solution: A solution ( $0.1 \mathrm{M} / \mathrm{L}$ citrate); B solution ( $0.1 \mathrm{M} / \mathrm{L}$ sodium citrate);

- Working solution: A solution of $9 \mathrm{ml}$ with B solution of $41 \mathrm{ml}$ in addition to distilled water of $450 \mathrm{ml}$;

- Diaminobenzidine (DAB) immunohistochemistry kit: purchased from LAB VISION, America;

- Streptavidin-Peroxidase (SP) immunohistochemistry reagent: purchased from Maifa Biological Technology Company, China.

\subsection{Major Instruments}

- Paraffin embedding machine: purchased from Sheldon, America;

- Letz1512 paraffin slicing machine: purchased from Leica, Germany;

- OLYMPUS upright microscope: purchased from Olympus, Japan.

\subsection{Methods}

The test specimen is the gastric cancer tissue specimens of the gastrointestinal surgical resection from the Sichuan Provincial People's Hospital from April 2005 to December 2007. According to the database record of the gastric tissue and follow-up visits, there are a total of 186 cases of paraffin-embedded specimens. Based on the situation whether there is lymph node metastasis, the specimens are divided into two groups: lymph node metastasis $\mathrm{N}(+)$ and without lymph node metastasis $\mathrm{N}(-)$.

\subsection{Preparation of Paraffin Slices}

The gastric cancer tissues are embedded in paraffin blocks, sliced into sections of $3 \mu \mathrm{m}$ thickness, attached to clean poly-lysine-coated films and then put into the clip box at room temperature for future use.

\subsection{HE Staining}

Regular dewaxed to water: Slice the tissue embedded in paraffin and put them into an oven of $65^{\circ} \mathrm{C}$ and bake overnight. Place them into xylene to dewax on the next day, 10 minutes in xylene I and xylene II respectively, following the step of gradient alcohol hydration, 2 minutes every time in ethanol for twice and then 2 minutes in 95\% ethanol, 80\% ethanol, 70\% ethanol and water respectively.

Put the slices into the hematoxylin staining solution for 5 to 10 minutes.

Gently rinse the slices with tap water for 5 to 10 minutes.

Acidify the slices in the $2 \%$ hydrochloric acid alcohol for 10 seconds and then gently rinse them with tap water for about 10 minutes.

Put the slices in the 1/500 ammonia until the slices turn blue for 20 seconds and then immediately gently rinse them with tap water for 4 - 5 minutes (with distilled water once).

Dye the slices in the $0.5 \%$ - $1 \%$ eosin staining solution for $3-5$ minutes and gently rinse them with tap water once.

And then it is gradient alcohol dehydration with $80 \%$ alcohol, 95\% alcohol and 100\% alcohol for 2 minutes each, followed by put them in xylene I and II for 10 minutes each.

Use neutral gum to fix the slices.

\subsection{Immunohistochemistry Staining}

Regular dewaxed to water: Slice the tissue embedded in paraffin and put them into an oven of $65^{\circ} \mathrm{C}$ and bake overnight. Place them into xylene to dewax on the next day, 10 minutes in xylene I and xylene II respectively, following the step of gradient alcohol hydration, 2 minutes every time in ethanol for twice and then 2 minutes in 95\% ethanol, 80\% ethanol, 70\% ethanol and water respectively.

Configurate fresh antigen retrieval solution for paraffin slices to perform antigen retrieval.

Put the slices into PBS solution and then gently wash for five minutes on the vibrating shaker which shall be repeated three times.

Configurate peroxidase blocking solution, and endogenously block the paraffin slices for 10 minutes.

Put the slices into PBS solution and then gently wash for five minutes on the vibrating shaker which shall be 
repeated three times.

Configurate fresh $10 \%$ non-immune system animal blood serum blocking solution and block the nonspecific antigen of the paraffin slices for 5 minutes.

Put the slices into PBS solution and then gently wash for five minutes on the vibrating shaker which shall be repeated three times.

According to the primary antibodies manual, respectively anti-dilute and configurate fresh primary antibodies working solution.

Add the primary antibodies and put the slices in a $4^{\circ} \mathrm{C}$ refrigerator overnight. The next day, get the slices out at room temperature for an hour.

Configurate biotinylated secondary antibodies working solution $50 \mathrm{ml}$ and drop it on the slices for 10 minutes' incubation.

Put the slices into PBS solution and then gently wash for five minutes on the vibrating shaker which shall be repeated three times.

Add 50 microliters of streptavidin peroxidase and incubate for 10 minutes.

Put the slices into PBS solution and then gently wash for five minutes on the vibrating shaker which shall be repeated three times.

Configurate 100 microliters fresh DAB TMB substrate solution and render at room temperature for 3 - 5 minutes (Perform a real-time observe the rendering process under the microscope).

Finally, redye the slices with hematoxylin solution.

And then it is gradient alcohol dehydration with $80 \%$ alcohol, $95 \%$ alcohol and $100 \%$ alcohol for 2 minutes each, followed by put them in xylene I and II for 10 minutes each.

Use neutral gum to fix the slices.

Replace the primary antibodies working solution with PBS as the negative blank contrast and replace the secondary antibodies working solution with normal serum as the blank contrast. An anti-dilution ratio of the primary antibodies working fluid is as follows in order: VEGF-CIg (McAb) 1:100, VEGFR-3 (McAb) 1:100, CD34 (McAb) 1:100.

\subsection{Morphology Observation of the Slices}

Under the microscope, the positive expression of VEGF-C shows the rendered color of cytoplasm is brown; the positive expression of VEGFR-3 shows the rendered color of membrane is brown; the positive expression of CD34 shows the rendered color of membrane and cytoplasm is brown.

With a 100× microscope, calculate the cell numbers among 100 cancer cells which show the positive expression of VEGF-C or VEGFR-3 in five observations and calculate the ratio of positive expression cancer cells. Above $20 \%$ is the positive expression; $20 \%-40 \%$ is + ; $41 \%-60 \%$ is $++; 61 \%-80 \%$ is +++ ; and above $81 \%$ is ++++ .

Assessment of the staining result of CD34 and microvessel density (MVD) assessment: the staining result demonstrates a significant difference from normal epithelial cancer cells and other tissue components, among which the stained brown cells or cell clusters are assessed as a blood vessel or a branch structure not connected can be calculated as a blood vessel. The immunohistochemistry slices are first put under a low-magnification optical microscope to determine the three highest vascular density areas. And then use a high-magnification optical microscope to choose the four highest vascular density areas to count the blood vessels (The average size of every field of observation is $0.075 \mathrm{~mm}^{2}$ ). Take the average value of the average blood vessel number as the specimen and the calculation method of MVD is the same.

At least two or more pathologists observe the immunohistochemistry slices in a double-blind reading manner and record the number and distribution of cells that express positively and pathological type and immunohistochemical features, etc.

\subsection{Statistical Analysis of Experimental Data}

All the experimental data are processed and analyzed by the SPSS17.0 statistical software. The experimental results are expressed as mean \pm standard deviation $(X \pm S D)$, count data using the $\mathrm{X}^{2}$ test, measurement data using $t$ test. Between the positive and negative expression groups of VEGF and VEGFR-3, all the factors use $\mathrm{X}^{2}$ test and $t$ test. The relationship between lymph node metastasis status and various factors is analyzed with the 
use of bivariate logistics regression analysis; calculate the overall survival rate using Kaplan-Meier; compare the survival rate curves using Log rank and Breslow; the prognostic factors are analyzed using Cox regression, where $p<0.05$ is considered to have the statistical meaning.

\section{Results}

\subsection{Relationship between the Expression of VEGF-C and VEGFR-3 and Clinicopathologic Factors of Gastric Cancer}

Based on the situation of whether there is lymph node metastasis, divide the 186 cases into two groups, the positive lymph node metastasis $\mathrm{N}(+)$ and the negative lymph node metastasis $\mathrm{N}(-)$. There are no statistical differences between the two groups in terms of gender, age, tumor location, gross type, tumor size and histopathology, etc.; there are statistical differences in terms of the depth of invasion. Among the 186 cases, 90 are $\mathrm{N}(-)$ and 96 are $\mathrm{N}(+)$; the positive expression of VEGF-C is $54.83 \%(102 / 186)$, among which, $34.44 \%(31 / 90)$ is $\mathrm{N}(-)$ and $73.9 \%(71 / 96)$ is $\mathrm{N}(+)$, where $p=0.001$. In the total specimen, the positive expression of VEGFR-3 is $33.33 \%$ (62/186), 21.11\% (19/90) as $\mathrm{N}(-)$ and 44.78\% (43/96) as $\mathrm{N}(+)$, where $p=0.001$, shown in Table 1.

The positive expression rates of VEGF-C and VEGFR-3 both grow with the increasing clinical stages. The positive expression rate differences of VEGF-C in different clinical stages have statistical significance $(p<0.05)$; the positive expression rate differences of VEGFR-3 in different clinical stages do not have statistical significance, shown in Table 2.

The expression of VEGF-C in cytoplasm of gastric cancer is shown as Figure 1 and Figure 2; the expression of VEGFR-3 in lymphangial endothelial cell membrane is shown as Figure 3 and Figure 4.

\subsection{Relationship between Microvessel Density and Lymphatic Vessel Density and Lymph Node Metastasis and VEGF-C}

To evaluate microvessel density (MVD) with CD34, there are no statistical differences between $\mathrm{N}(-)$ and $\mathrm{N}(+)$. To evaluate lymphatic vessel density (LVD) with the staining situation of microlymphatic vessel, LVD of N(-) is $18.46 \pm 7.4$; $\mathrm{LVD}$ of $\mathrm{N}(+)$ is $26.23 \pm 8.2$, with a significant difference $(\mathrm{t}=-2.427, p=0.016)$. Divide the two groups of cases based on whether there is the expression of VEGF-C and there are no statistical differences of the average MVD between the two groups and there are statistical differences of the average LVD between the two groups, respectively $18.12 \pm 10.01$ and $25.89 \pm 13.28(\mathrm{t}=-2.449, p=0.015)$, shown in Figure 5 and Figure 6.

The expression of CD34 in vascular endothelial cell membrane and cytoplasm is shown as Figure 7 and Figure 8.

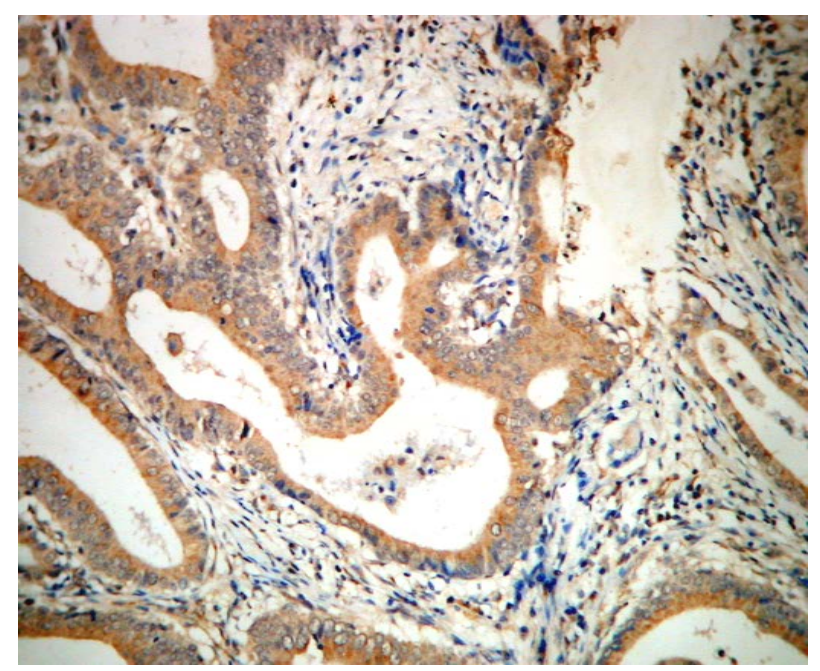

Figure 1. Positive expression of VEGF-C in cytoplasm of gastric cancer (original magnification: $\times 200$ ). 


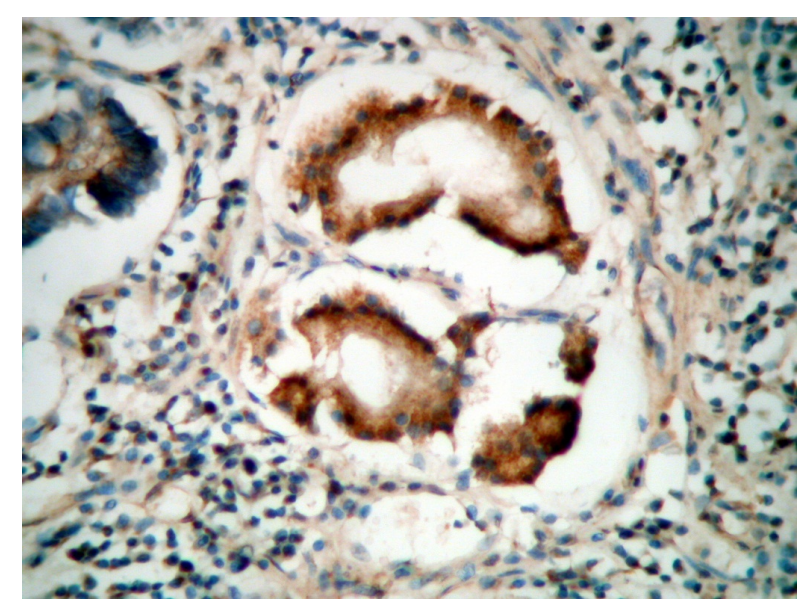

Figure 2. Positive expression of VEGF-C in cytoplasm of gastric cancer in metastatic lymph node (original magnification: $\times 400$ ).

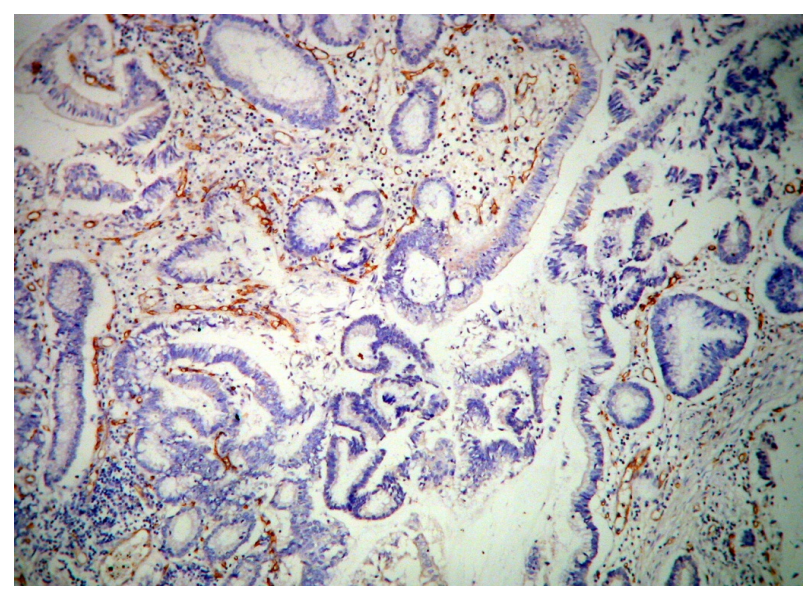

Figure 3. The expression of VEGFR-3 in lymphangial endothelial cell adjacent gastric cancer tissues (original magnification: $\times 100)$.

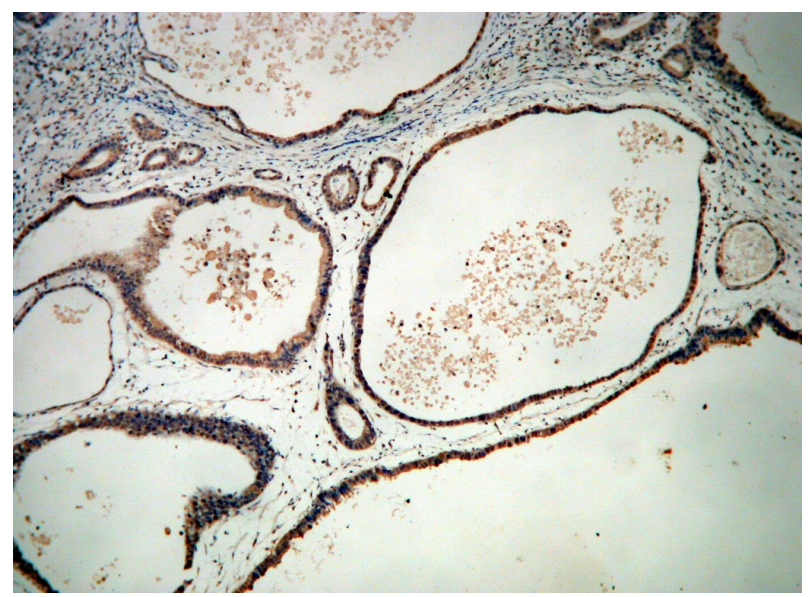

Figure 4. The expression of VEGFR-3 in lymphangial endothelial cell of metastatic lymph node (original magnification: $\times 100)$. 
Table 1. Relationship between lymph node metastasis and clinicopathologic factors of gastric cancer.

\begin{tabular}{|c|c|c|c|}
\hline \multicolumn{4}{|c|}{ Cases } \\
\hline Clinicopathologic factors & $\begin{array}{l}\text { Lymph node metastasis } \\
\qquad(\mathrm{n}=96)\end{array}$ & $\begin{array}{l}\text { Non-lymph node metastasis } \\
\qquad(\mathrm{n}=90)\end{array}$ & $p$ value \\
\hline Gender & & & 0.355 \\
\hline Male & 74 & 65 & \\
\hline Female & 22 & 25 & \\
\hline Age & & & 0.388 \\
\hline$\leq 60$ & 52 & 56 & \\
\hline$>60$ & 44 & 34 & \\
\hline Tumor location & & & 0.412 \\
\hline Upper stomach $1 / 3$ & 25 & 17 & \\
\hline Middle stomach $1 / 3$ & 16 & 17 & \\
\hline Lower stomach $1 / 3$ & 55 & 56 & \\
\hline Gross type & & & 0.233 \\
\hline Borrmann I & 6 & 8 & \\
\hline Borrmann II & 26 & 32 & \\
\hline Borrmann III & 57 & 41 & \\
\hline Borrmann IV & 7 & 9 & \\
\hline Tumor size & & & 0.288 \\
\hline$\leq 4 \mathrm{~cm}$ & 59 & 63 & \\
\hline$>4 \mathrm{~cm}$ & 37 & 27 & \\
\hline Tumor depth & & & 0.001 \\
\hline pT1 & 7 & 34 & \\
\hline pT2 & 21 & 27 & \\
\hline pT3 - 4 & 68 & 29 & \\
\hline Differentiation degree & & & 0.155 \\
\hline High & 4 & 13 & \\
\hline Medium & 30 & 26 & \\
\hline Low & 62 & 51 & \\
\hline Clinical stage & & & 0.0001 \\
\hline I & 7 & 45 & \\
\hline II & 17 & 25 & \\
\hline III & 52 & 17 & \\
\hline IV & 20 & 3 & \\
\hline Expression of VEGF-C & & & 0.001 \\
\hline Positive & 71 & 31 & \\
\hline Negative & 25 & 59 & \\
\hline Expression of VEGFR-3 & & & 0.001 \\
\hline Positive & 43 & 19 & \\
\hline Negative & 53 & 71 & \\
\hline
\end{tabular}


Table 2. Relationship between the expression of VEGF-C and VEGFR-3 and clinicopathologic factors of gastric cancer.

\begin{tabular}{|c|c|c|c|c|c|c|c|}
\hline \multirow{2}{*}{ Clinicopathologic factors } & \multirow{2}{*}{ Cases } & \multicolumn{2}{|c|}{ Expression of VEGF-C } & \multirow{2}{*}{$p$ value } & \multicolumn{2}{|c|}{ Expression of VEGFR-3 } & \multirow{2}{*}{$p$ value } \\
\hline & & Positive & Negative & & Positive & Negative & \\
\hline Gender & & & & 0.231 & & & 0.228 \\
\hline Male & 139 & 80 & 59 & & 50 & 89 & \\
\hline Female & 47 & 22 & 25 & & 12 & 35 & \\
\hline Age & & & & 0.849 & & & 0.329 \\
\hline$\leq 60$ & 108 & 60 & 48 & & 33 & 75 & \\
\hline$>60$ & 78 & 43 & 35 & & 30 & 48 & \\
\hline Tumor location & & & & 0.061 & & & 0.628 \\
\hline Upper stomach 1/3 & 42 & 32 & 10 & & 17 & 25 & \\
\hline Middle stomach $1 / 3$ & 33 & 12 & 21 & & 11 & 22 & \\
\hline Lower stomach $1 / 3$ & 111 & 59 & 52 & & 35 & 76 & \\
\hline Gross type & & & & 0.012 & & & 0.777 \\
\hline I & 14 & 10 & 4 & & 6 & 8 & \\
\hline II & 59 & 27 & 32 & & 18 & 41 & \\
\hline III & 96 & 61 & 35 & & 36 & 60 & \\
\hline IV & 17 & 5 & 12 & & 3 & 14 & \\
\hline Tumor depth & & & & 0.028 & & & 0.122 \\
\hline pT1 & 40 & 17 & 23 & & 10 & 30 & \\
\hline pT2 & 49 & 24 & 25 & & 13 & 36 & \\
\hline pT3 - 4 & 97 & 62 & 35 & & 39 & 58 & \\
\hline Differentiation degree & & & & 0.614 & & & 0.244 \\
\hline High & 16 & 7 & 9 & & 4 & 12 & \\
\hline Medium & 57 & 30 & 27 & & 16 & 41 & \\
\hline Low & 113 & 65 & 48 & & 43 & 70 & \\
\hline Clinical stage & & & & 0.002 & & & 0.072 \\
\hline I & 52 & 24 & 28 & & 14 & 38 & \\
\hline II & 41 & 15 & 26 & & 10 & 31 & \\
\hline III & 70 & 47 & 23 & & 29 & 41 & \\
\hline IV & 23 & 17 & 6 & & 11 & 12 & \\
\hline Lymph node metastasis & & & & 0.0001 & & & 0.002 \\
\hline Positive & 96 & 71 & 25 & & 43 & 53 & \\
\hline Negative & 90 & 31 & 59 & & 19 & 71 & \\
\hline
\end{tabular}

Note: $\mathrm{X}^{2}$ test. 


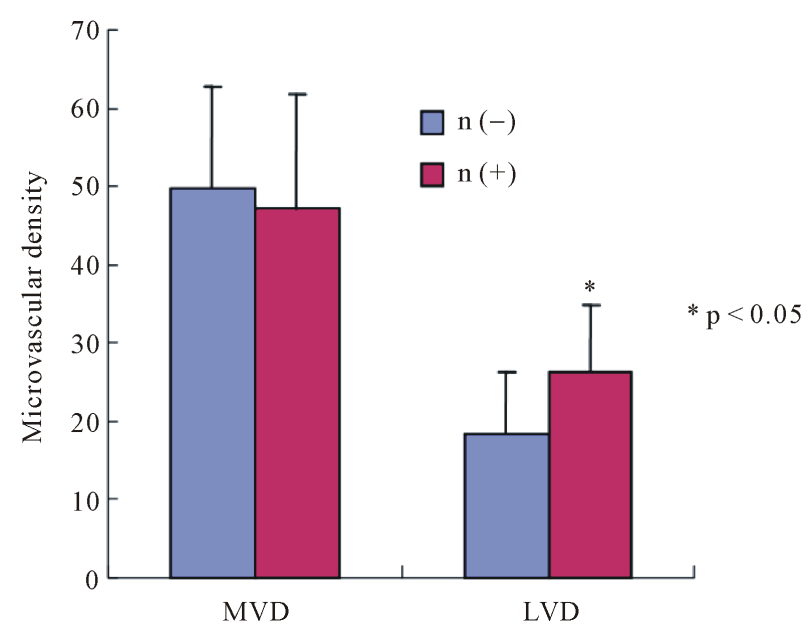

Figure 5. Relationship between MVD and LVD and lymph node metastasis.

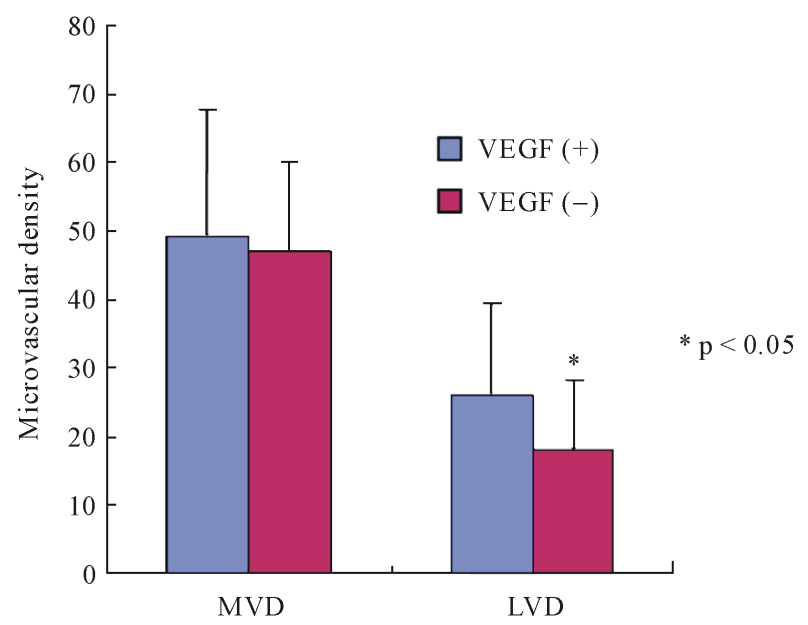

Figure 6. Relationship between MVD and LVD and the expression of VEGF-C.

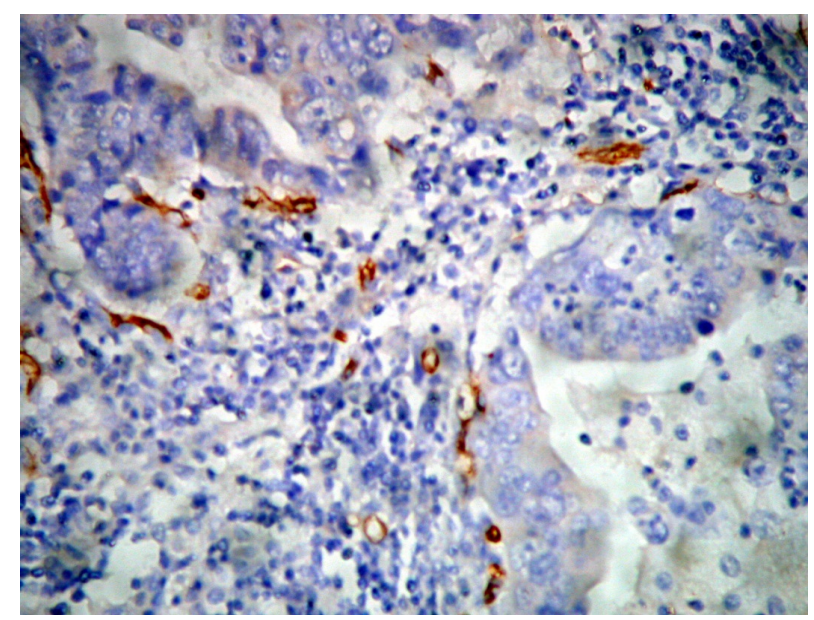

Figure 7. Expression of CD34 in vascular endothelial cell of gastric cancer (original magnification: $\times 400$ ). 


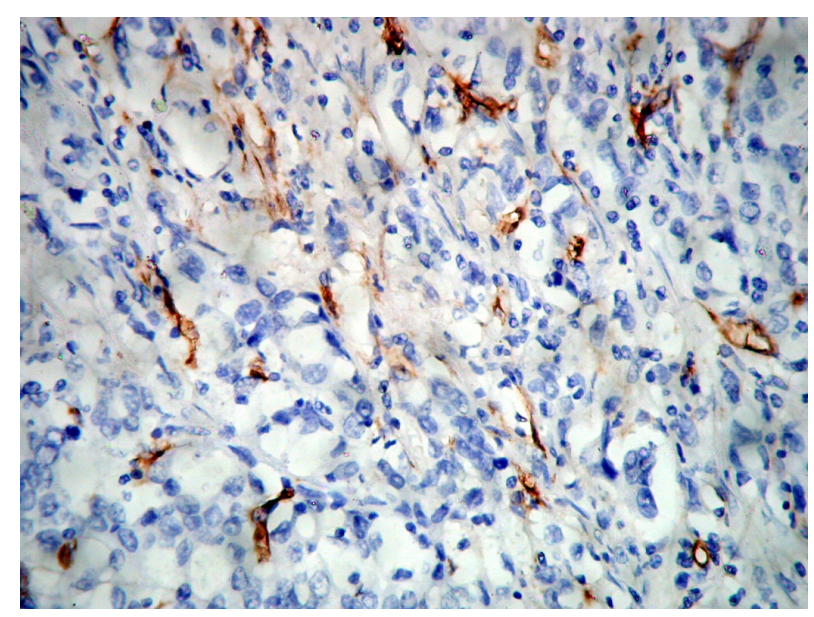

Figure 8. Expression of CD34 in vascular endothelial cell adjacent gastric cancer tissues (original magnification: $\times 400$ ).

\subsection{Relationship between the Expression of VEGF-C and VEGFR-3 and Five-Year Cumulative Survival Rate}

In the experiment, the five-year overall survival rate of the positive group $\mathrm{N}(+)$ of lymph node patients is $31 \%$ and the negative group is $66 \%$ so that there are statistical differences between the two groups (Log rank $=27.15$, $p=0.001$ ). To divide the cases based on the situation whether there is the expression of VEGF-C, the five-year overall survival rates of the two groups are $36 \%$ (the expression of VEGF-C is positive) and $59 \%$ (the expression of VEGF-C is negative) with the statistical differences (Log rank $=27.15, p=0.001$ ); to divide the cases based on the situation whether there is the expression of VEGFR-3, the five-year overall survival rates of the two groups are $31 \%$ (the expression of VEGFR-3 is positive) and $43 \%$ (the expression of VEGFR-3 is negative), with the statistical differences (Log rank $=5.241, p=0.041$ ). In the further subgroup analysis, in the group of positive expression of VEGF-C, the five-year overall survival rate of non-expression of VEGFR-3 is $43 \%$ and the five-year overall survival rate of expression of VEGFR-3 is 31\%, with the statistical differences (Log rank = $2.273, p=0.032$ ); and in the group of negative expression of VEGF-C, the five-year overall survival rate of the negative expression of VEGFR-3 is $66 \%$ and the five-year overall survival rate of the positive expression of VEGFR-3 is 44\%, with the statistical differences ( $\log$ rank $=0.001, p=0.697$ ), see Table 3 and Figure 9, Figure 10 and Figure 11.

In the binary logistic regression analysis, the lymph node metastasis is the dependent variable, among which, the negative lymph node metastasis is set to be 0 and the lymph node metastasis is set to be 1 ; the independent variables include gender of patients, age, Borrmann type, tumor location, invasion depth, differentiation degree, TNM stage, invasion to adjacent organs, and the expression of CD34, VEGF-C and VEGFR-3. Backward: use the LR method to select the covariates and the inspection deletion covariate standard is $\alpha=0.10$ (default value). After Step 13 selection process, delete gender, age, tumor location, Borrmann type, invaded adjacent organs and CD34 (MVD) of the covariates and ultimately retain covariates in the model as the analysis results, which are VEGF-C, VEGFR-3, differentiation degree, invasion depth and TNM stage, see in Table 4. The OR values of the covariates in the model VEGF-C, VEGFR-3, differentiation degree, invasion depth and TNM stage are respectively RVEGF-C $=4.684$, ORVEGFR-3 $=1.408$, OR differentiation degree $=1.154$, OR invasion depth $=$ 1.352 and ORTNM stage $=2.566$. Since all five OR values are above 1 , they are the dangerous factors for lymph node metastasis. The final equation for the logistic regression prediction is

$$
\mathrm{P}(1)=1 /\left[1+\mathrm{e}^{-(-4.362+3.684 \text { VEGF-C }+0.408 \text { VEGFR-3+0.154differentiation degree+ }+0.352 \text { invasion depth }+1.566 \mathrm{TNM} \text { stage })}\right] \text {. }
$$

In the Cox regression analysis of 186 gastric cancer patients, the dependent variable is the survival time of the follow-up patients; the independent variables are consisted of the patients' gender, age, tumor location, Borrmann type, differentiation degree, invasion depth, lymph node metastasis, lymph node metastasis station, liver metastasis, lymph node dissection scope, combined organ resection, operative time, blood transfusion, tumor 


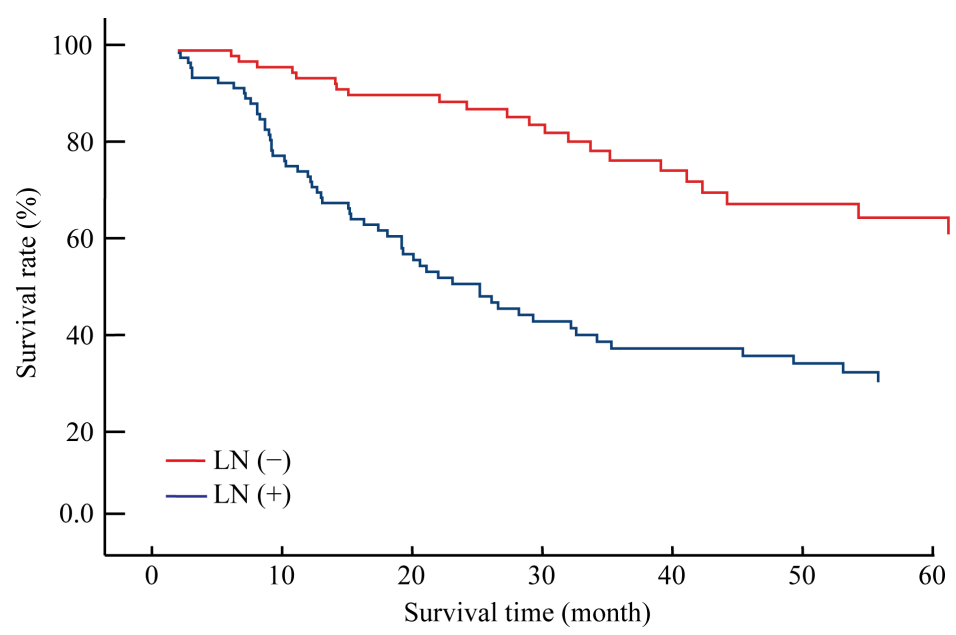

Figure 9. Relationship between survival time of gastric cancer and lymph node metastasis.

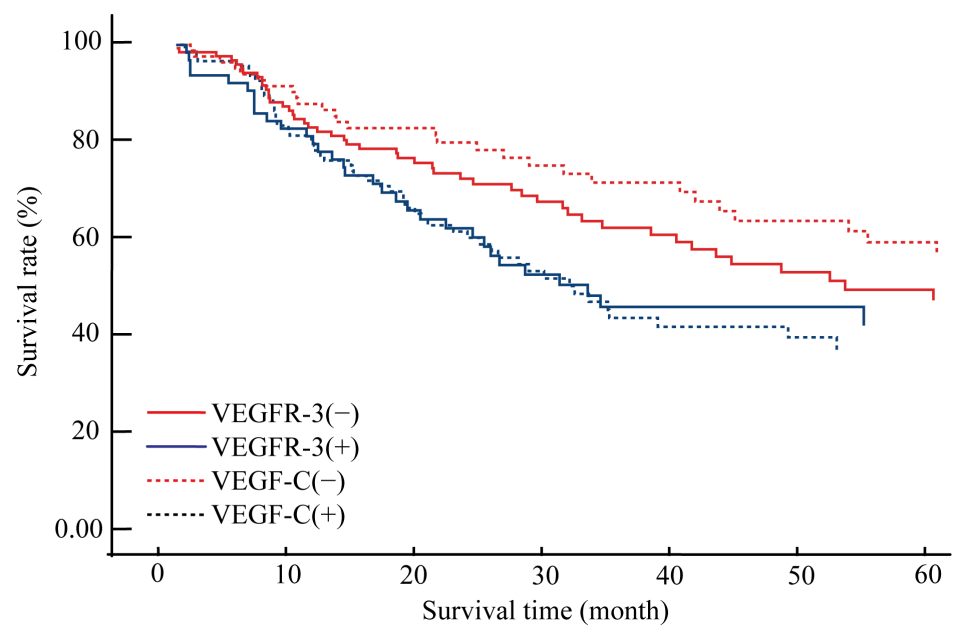

Figure 10. Relationship between survival time of gastric cancer and the expression of VEGF-C and VEGFR-3.

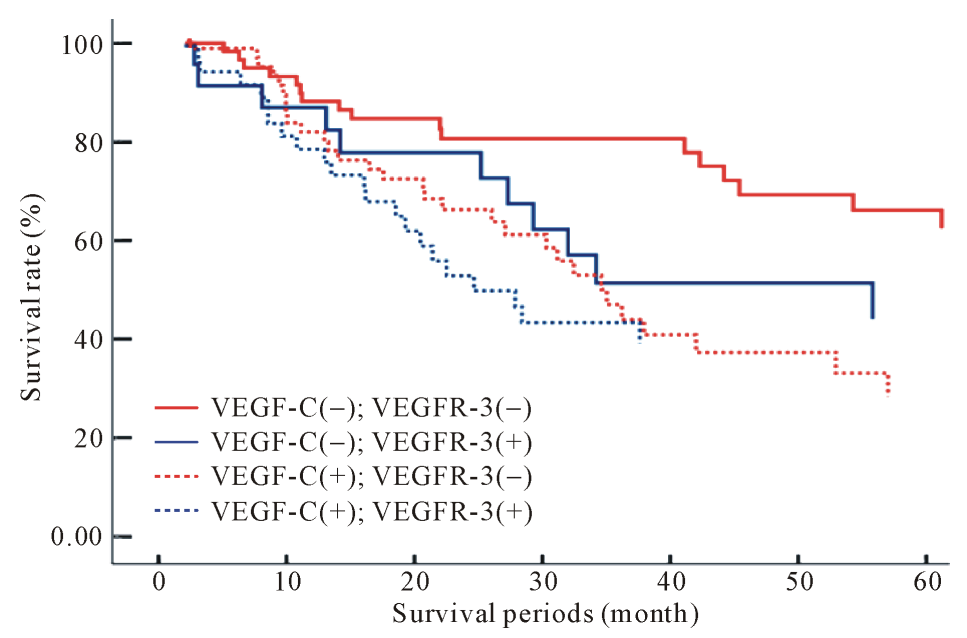

Figure 11. Relationship between the time and the expression of VEGF-C and VEGFR-3. 
Table 3. Relationship between the expression of VEGF-C and VEGFR-3 and five-year cumulative survival rate.

\begin{tabular}{|c|c|c|c|c|c|}
\hline Indector & Five-year survival rate & Logrank Chi-square & $p$ & Breslow Chi-square & $p$ \\
\hline Lymph node & & 27.15 & 0.0001 & 29.53 & 0.0001 \\
\hline $\mathrm{LN}(-)$ & $66 \%$ & & & & \\
\hline $\mathrm{LN}(+)$ & $31 \%$ & & & & \\
\hline VEGF-C & & 8.638 & 0.003 & 8.183 & 0.004 \\
\hline VEGF-C(-) & $59 \%$ & & & & \\
\hline VEGF-C(+) & $36 \%$ & & & & \\
\hline VEGFR-3 & & 5.241 & 0.041 & 5.263 & 0.0423 \\
\hline VEGFR-3(-) & $50 \%$ & & & & \\
\hline VEGFR-3(+) & $42 \%$ & & & & \\
\hline VEGF-C $(+)$ & & 2.273 & 0.032 & 2.281 & 0.031 \\
\hline VEGFR-3(-) & $43 \%$ & & & & \\
\hline VEGFR-3(+) & $31 \%$ & & & & \\
\hline VEGF-C(-) & & 0.001 & 0.697 & 0.219 & 0.639 \\
\hline VEGFR-3(-) & $66 \%$ & & & & \\
\hline VEGFR-3(+) & $44 \%$ & & & & \\
\hline
\end{tabular}

Table 4. Binary logistic regression analysis results of lymph node metastasis.

\begin{tabular}{cccccccccc}
\hline Step 13 & B & S.E & Wald & df & Sig & Exp(B) & \multicolumn{2}{c}{$95.0 \%$ C.I. for Exp(B) } \\
\cline { 6 - 9 } VEGF-C & 1.544 & 0.435 & 12.613 & 1 & 0.0001 & 4.684 & 1.988 & 10.982 \\
VEGFR-3 & 0.342 & 0.105 & 10.534 & 1 & 0.001 & 1.408 & 1.145 & 1.730 \\
Invasion & 0346 & 0.356 & 9.436 & 1 & 0.033 & 1.708 & 1.352 & 1.402 \\
Grade & 0.249 & 0.302 & 10.817 & 1 & 0.093 & 1.002 & 1.154 & 1.799 \\
TNM stage & 0.942 & 0.172 & 31.044 & 1 & 0.000 & 2.566 & 1.832 & 3.595 \\
Constand & -4.362 & 0.705 & 38.266 & 1 & 0.000 & 0.013 & & & \\
\hline
\end{tabular}

size, TNM stage, expression of VEGF-C and VEGFR-3 and microvessel density. By using the forward stepwise covariates, the standard of covariates is $\alpha=0.05$ (default value) and it has to take 13 steps, including the expression of VEGFR-3 and VEGF-C, lymph node metastasis, liver metastasis, invasion depth, lymph node dissection scope, intraoperative blood transfusion, and the age of patients ultimately retained in the model covariates. The results show that the OR values of invasion depth of tumors, lymph node metastasis, liver metastasis, intraoperative blood transfusion, and the expression of VEGF-C and VEGFR-3 are all greater than 1 so that they are the dangerous factors to reduce the patients' survival time, but the OR values of the lymph node dissection scope and the patients' ages are both smaller than 1 so that they are the protective factors to increase the patients' survival time. The final risk function is

$h(t)=\left[h_{0}(t)\right] \mathrm{e}^{(0.726 \text { lymph node metastasis+0.691invasion depth+0.077VEGFR-3+0.469VEGF-C+0.704liver metastasis-0.403lymph node dissection-0.345age+0.01blood transfusion })}$, see Table 5 . 
Table 5. Cox regression proportional hazard regression.

\begin{tabular}{cccccccccc}
\hline Step 10 & B & SE & Wald & df & Sig & Exp(B) & \multicolumn{2}{c}{ 95.0\% CI for Exp(B) } \\
\cline { 6 - 8 } Lower & Upper \\
\hline Lymph node metastasis & 0.726 & 0.273 & 7.095 & 1 & 0.008 & 2.066 & 1.211 & 3.525 \\
Invasion & 0.691 & 0.162 & 18.168 & 1 & 0.000 & 1.996 & 1.452 & 2.742 \\
VEGFR-3 & 0.077 & 0.036 & 4.680 & 1 & 0.031 & 1.080 & 1.07 & 1.158 \\
VEGF-C & 0.469 & 0.177 & 7.009 & 1 & 0.008 & 1.599 & 1.130 & 2.263 \\
Hepatic metastasis & 0.704 & 0.363 & 3.749 & 1 & 0.053 & 2.021 & 0.991 & 4.122 \\
Lymph node dissection & -0.403 & 0.150 & 7.195 & 1 & 0.007 & 0.668 & 0.497 & 0.897 \\
Age & -0.345 & 0.113 & 9.401 & 1 & 0.002 & 0.708 & 0.568 & 0.883 \\
Volume of blood transfusion & 0.01 & 0.000 & 25.534 & 1 & 0.000 & 1.001 & 1.001 & 1.002 \\
\hline
\end{tabular}

\section{Discussion}

The death rate of gastric cancer ranks first among a variety of tumors and thus it is imperative for the prevention of gastric cancer. Clinical studies have shown that after the perform of radical gastrectomy, the five-year survival rate of patients with early gastric cancer is $90 \%$, while the rate of patients with advanced is only $40 \%$, among which some patients die of local recurrence and metastasis. This has also shown that the metastasis which cannot be determined by the current morphological diagnostic techniques during the process of treatment, which is micrometastasis. A variety of clinicopathological studies have indicated that lymph node metastasis is one of the major ways for the solid tumors to disseminate; in the early stages of gastric cancer, the dissemination of the regional lymph node for the tumor cells already exist. In the recent years, the continuous findings by researchers and studies of the specific marker of the lymphatic endothelial cell are helpful for the basic study of the gastric cancer lymphangiogenesis and deep exploration of the molecular mechanisms of the lymph node metastasis, which not only can provide an important basis to determine the prognosis for the gastric cancer patients, but also can provide a more solid theoretical basis for the future targeted therapies.

Regarding tumor metastasis, people always focus on tumor angiogenesis and new vessel research without the emphasis on the research of tumor lymphangiogenesis, the main reason of which is that there is lack of specificity of the identification of the markers of lymphangiogenesis. Regarding the phenomenon that the lymph vessels surrounding the tumor often expand and penetrate the tumor, it has been unclear whether the expanded lymph vessels are the lymphangiogenesis after the tumor or before the tumor. Some scholars think the increased mesenchyme pressure within the tumor differ the lymph vessels' structure and functions within the tumor from the surrounding normal lymph vessels so that there are lack of functional lymph vessels within the tumor. Recent studies have demonstrated that with the expression of the lymphangiogenesis factors VEGF-C and VEGF-D, etc., especially by VEGF-C, VEGF-D/VEGFR-3 pathway, the cancer cells can induce lymphangiogenesis and further promote cancer lymphatic metastatic cells. These findings make lymphangiogenesis become the research focus of studying lymphatic metastasis and there may be in the treatment of lymphatic metastasis of tumor targets [9]-[11]. In 1627, Caspar Asellius [12] found out the existence of human lymphatic system including lymph vessel, lymph node, lymph organs (tonsil, spleen, thymus), lymphoid tissue and circulating lymph cells. Lymphatic system and blood vessel system are important parts of the body microcirculation. They coordinate and co-influence to compose the body's vascular system and maintain the stability of an internal environment. The lymphatic system is the initial way of metastasis for the malignant tumors [13]. The malignant tumors invade the lymphatic system by firstly transferring to the regional lymph nodes. Gastric cancer is one of the most common malignant tumors in East Asia. The early lymph node metastasis rate can reach 10\% - 15\% [14]. With the continuous development of the basic medical science, the study of lymphangiogenesis of gastric cancer and molecular mechanisms of lymph node metastasis become deeper, which makes the lymph node metastasis targeted therapies more valuable.

In 1983, Senger et al. [15] purified a certain substance that can enhance the microvascular permeability from 
malignant ascites of line 10 tumor-bearing guinea pigs and tumor cell culture fluid. In 1989, Gospodarowicz et al. [16] [17] found a certain substance that can significantly promote endothelial cell mitosis from the normal bovine pituitary folliculo stellate cell culture fluid. Both substances were later proved to be vascular endothelial growth factor (VEGF). So far, the members of VEGF family include VEGF-A, VEGF-B, VEGF-C, VEGF-D, VEGF-E, VEGF-F and PIGF, a total of seven kinds [18]. They correspond with the specific receptors to start downstream biological effects. The VEGF specific receptors are all transmembrane protein tyrosine kinases, whose extracellular portion contains ligand binding domain, whose middle portion is transmembrane area and whose intracellular portion includes the catalytic domain of the protein tyrosine kinase. When combined with ligand, the homologous or heterologous dimerization occurs within the two receptors, which automatically induces phosphorylation. This phosphorylation mainly occurs on the conserved tyrosine residues in the two dimers of the kinase domain. The phosphorylation of tyrosine residues not only can greatly increase the activity of the receptor tyrosine kinases, but also every receptor has multiple phosphorylation sites which can provide enough berthing sites for downstream kinases or proteins. So far, five specific tyrosine kinases receptors of the VEGF family have been found, which are VEGFR1 (also known as Flt-1), VEGFR-2 (also known as Flk/KDR), VEGFR-3 (also known as Flt-4), Neuropilins-1 (Nrp-1) and Neuropilins-2 (Nrp-2). Studies of molecular mechanisms have found that VEGF not only can stimulate the proliferation and migration of vascular endothelial cells in tumors, induce angiogenesis, increase vascular permeability, promote growth of tumor cells, promote infiltration of mononuclear cells, fibroblasts, endothelial cells and other cells and cause the surrounding tissue fibers composed of proteins by paracrine pathwaythat are helpful for the formation of tumor extracellular matrix, easier for the tumor cells to invade into the new blood vessels andmakes the tumor cells more invasive, but also canpromote the proliferation and migration of tumor cells by autocrine pathways which makes the tumor cells more invasive [19].

In the recent years, there have been many studies about the relationship of the formation of new blood vessels and lymphatic vessels with VEGF pathway and the functions in the process of tumor growth, which have proved that they are closely associated with the growth and metastasis of tumors. In 1996, in the use of optical chromatography, Joukov et al. firstly isolated and cloned VEGF-C, the new member of VEGF/PDGF family from human prostate cancer cell line PC-3 cDNA library [20]. Lee et al. also isolated the corresponding gene and named it the vascular endothelial growth factor related protein (VRP) [21]. At first, VEGF-C secrets in cytoplasm in the form of protein precursor and then is processed and activated by proproteinconvertases 5 and 7 [22]. The subunit, combined by VEGF-C and its specific receptor, is a dimer with molecular weight of $3.1 \times 10^{4}, 2.9 \times 10^{4}$ and connected by a disulfide bond. When it is secreted outside the cell, it can be immediately hydrolyzed into a small subunit with a molecular weight of $2.1 \times 10^{4}$ and not linked by a disulfide bond by plasminogen and relevant proteolytic enzymes [23]. The weak expression of VEGF-CmRNA can be detected in the heart, skeletal muscle, lymph node, placenta, ovary, small intestine and oarium. The cytokines like IL-1A, IL-1B, IL-6 and TNF-A and platelet-derived growth factor (PDGF), epidermal growth factor (EGF), transforming growth factor-B (TGF-B) and insulin-like growth factor-1 (IGF-1) all can promote transcription of VEGF-C mRNA. Some steroids are able to decrease VEGF-C mRNA transcription [24]. VEGF-C plays a major role in the VEGFR-3/ flt-4 receptors of tyrosine kinases [25], in particular on the occurrence of lymphangiogenesis [26]. VEGFR-3 is the first verified lymphatic marker, cloned from human leukemia cells and human placenta, which is necessary for the development and survival of lymph vessels and is the specific marker for the mature lymphatic endothelial cells. VEGFR-3 gene is located on chromosome $5 q 33$ - q35, encoding a polypeptide of two polymer chains of cell surface glycoproteins. The protein locates on the extracellular tyrosine kinase receptor [20]. At the same time, the expression of VEGFR-3 has the time-specific characteristic [27]. It is expressed in the cardiovascular system in the early embryonic development, only expressed in the lymphatic endothelium in the adult period and can also be expressed in the new blood vessels in certain pathological conditions. When VEGFR-3 is bonded with its specific ligand, after the enlargement of a series of signaling cascades, it can activate the signal pathway between MEK/ERK of lymphatic endothelial cells and PI3K/Akt, activate DNA replication of lymphatic endothelial cells and promote the proliferation, migration and division of lymphocyte [28].

\subsection{Tumor and Lymphangiogenesis}

Lymphangiogenesis is the process of further development and reproduction of the original lymphatic vessels to new lymphatic vessels. The process exists in the conditions of embryonic growth, inflammation, tissue repair 
and parasitic infections under, etc. [29]-[31]. Compared with the corresponding blood vessels, the lymphatic vessels have significant differences in the functions and ultrastructure. Lymphatic capillaries are composed of a layer of lymphatic endothelial cells and relatively thin connective tissue. Due to excessive stretching of lymphatic endothelial cells, the tube wall becomes thinner. The width of the lumen is about the three times of capillary and show a more irregular shape. The connection between endothelial cells tends to be more simplistic with more open connections and reduced tight junctions, which creates a high degree of permeability of the lymphatic wall and makes it easier for macromolecules and lymphocytes to go into. The lymphatic system is suitable for cells to enter and transport, which provides a convenient condition for the invasion and metastasis of tumor cells [32]. So far, about the existence of new lymphatic vessels within the tumor, whether it is part of the tumor vasculature, functions, whether lymphangiogenesis can lead to lymph node metastasis of tumor cells, whether the structure of the new lymphatic vessels is different from that of the original lymphatic vessels, and whether the differences can make it easier for lymph node metastasis of the tumor cells [33] and other issues, there are very different perspectives [34]. Some present studies have demonstrated the existence of lymphatic vessels in the tumor and the tissues surrounding it [35], but there is no evidence to prove whether the lymphatic vessels exist before the tumor, or induced by the tumor. There is a more important question whether these lymphatic vessels within the tumor really have the corresponding functions [36].

There are many hypotheses about the original of lymphatic vessels, and right now there are two major points of view. One hypothesis is that the lymphatic vessels are differentiated from the stroma precursor cells-embryonic cells of lymphatic vessels within mesenchyme; the other hypothesis is that the lymphatic network comes from the vesicle of the embryonic vein endothelial cells in the way of regional budding. With the reveal of the specific molecular markers of the lymphatic vessels and the corresponding growth elements, the exploration of the lymphangiogenesis molecular mechanism has entered into a new phase. The over expression of VEGF-C can promote the continuous lymphangiogenesis and lead to lymph node metastasis. VEGFR-3 (Flt-4) is mainly expressed in adults' lymphatic endothelium cell [37] and point mutations can lead to the consequence of hereditary lymphedema [38]. VEGFR-3 is also directly involved in the occurrence of embryonic blood vessels and lymphatic vessels [20]. The interaction of VEGF-C with the over expression of VEGFR-3 in the mice skin in the way of transgene can result in the proliferation of lymphatic endothelial cells and the expansion of lymphatic vessels [39]. Correlational studies have found VEGF-C and VEGFR-3 can simultaneously express in various tumor tissues [40] [41], and the expression of VEGF-C is closely related to the situation of vascular lymph node metastasis [42] [43]. VEGF-A cannot combine with VEGFR-3, which can only promote the generation of new blood vessels [44]. It proves the lymphangiogenesis generation must have VEGFR-3. VEGF-D is another lymphatic vessel growth factor, and can also be combined with VEGFR-3, which can promote the formation of lymphangiogenesis [45]. Through the staining detection of LYVE-1, Stacke et al. have found that VEGF-D can induce tumors to create lymphangiogenesis and promote tumor cells to spread and metastasis to the regional lymph node and this kind of lymph node spread can be stopped by the specific blocking antibodies of VEGF-D [46]. Studies about uterine tumors have also found that the expression level of VEGF-D and its receptor VEGFR-3 increases with the progress of uterine tumors andthe close relationship of the expression level of the two with myometrium invasion and lymph node metastasis is an important prognosis independent predictive factor of uterine tumors [47]. And thus, in the lymphatic systems of many solid tumors, the expressions and interactions of VEGF-C, VEGF-D and the receptor VEGFR-3 are very important for lymphangiogenesis.

\subsection{Lymphangiogenesis and Lymph Node Metastasis}

Lymphangiogenesis induced by the tumor promotes the occurrence of tumor cells' lymph node metastasis, wherein the endogenous VEGF-C is an important regulator of lymphangiogenesis which plays an important role. Based on the current series of experiments in animal models, VEGF-C plays an important role onlymphangiogenesis and tumor metastasis. Skobeand Yanai et al. [48] directly vaccinated tumor cells in the over expression of VEGF-C on the experiment animals, the results of which have demonstrated the existence of VEGF-C protein or polypeptide to promote more lymphangiogenesis and regional lymph node metastasis. Theresults have also revealed that VEGF-C promotes the generation of lymphangiogenesisin tumors rather than the generation of new blood vessels; the tumor cells in the over expression of VEGF-C can be transferred to the regional lymph node and lung and the tumor cells in the non-expression of VEGF-C do not have metastasis, which proves the function of VEGF-C in the promotion of tumor cell metastasis. Correlational studies also prove that VEGF-C 
and VEGFR-3 are highly expressed in lung cancer cell lines of lymph node metastasis and the two have a close positive correlation [49].

Currently, it is not very clear about the signal of VEGF-C/VEGFR-3 in tumor lymphangiogenesis and in the regulation mechanism of the precise factors in lymph node metastasis. However, it is clear that the lymphatic endothelial cells indeed participate in the generation of tumor lymphangiogenesis and lymph node metastasis. Its molecular mechanisms may be: 1) The structural features of lymphangiogenesis make it easier for the tumor cells to invade into the lymphatic system. Under an electron microscopy, the tumor lymphatic wall is irregular, endothelial cells swollen, organelles abnormal morphological, the connections of endothelial cells not tight and in a state of expansion open. 2) Some scholars believe the expression of VEGF-C in tumor cells and some chemotactic cytokines of biochemical reactions both participate in tumor cell metastasis; maybe the change of the activity of some adhesion molecules on lymphatic vessels can make thechemotactic ability of tumor cells and invasion power of lymphatic vessels stronger [50]. 3) Many studies have also revealed that the lymphatic hyperplasia and expansion in the expression of VEGF-C exists in the adjacent normal tissues of the tumor, but the open lymphatic vessels are not found in the center domain. Such expansion and proliferation of lymphatic vessels and lymphatic capillaries have a moreimportant function in tumor metastasis [51]-[53]. And thus, the interaction of VEGF-C and its specific receptor play an important role on tumor lymphangiogenesis and lymph node metastasis.

\subsection{Cliniclpathological Study of the Protein Expression of VEGF-C and VEGFR-3}

The expression of VEGF-C and its specific receptor VEGFR-3 in prostate cancer cells plays an important role on the overall development of prostate cancer. In corresponding studies of human prostate cancer, Tsurusaki et al. used in situ hybridization and found out VEGF-C mainly promoted lymphangiogenesis network in tumor tissues by its specific combination with its receptor VEGFR-3 and accordingly brought in lymph node metastasis [54]. A large number of clinical basic experiments demonstrate that the expression of VEGF-C and VEGFR-3 is increased in the solid tumors of breast, prostate, esophagus, stomach and colorectal cancer [55][58]; the expression of VEGFR-3 shows a positive correlation with the expression of VEGF-C and a negative relationship with the differentiation degree of the tumor, and it has a close relationship with tumor cell metastasis. The result also shows the high expression of VEGF-C and VEGFR-3 in gastric cancer tissues and the expression is closely related to lymph node metastasis $(p<0.05)$. The expression of VEGFR-3 mainly takes place in lymphatic vessels and lymphatic endothelialcells in the vicinity of the tumor. The expression of VEGFR-3 in the advanced tumors is obviously increased, which is closely associated with the lymphatic invasion of gastric cancer [59]. VEGF-C, VEGF-D and VEGFR-3 play an important role on lymph node metastasis, which can be used as an important prognostic evaluation index [60]. Da et al. found in an experiment that the positive expression rate of VEGF-C in gastric cancer cells was $54.4 \%$, which was a lot higher than the normal gastric cancer cells $(p<0.05)$ [61]. Through immunohistochemical method, VEGF-C is expressed both in colorectal cancer tissues and normal mucosa tissues [62], which shows the expression is very high in 89\% (70/79) adenomas tissues and the expression level of adenomas occurred in mucosal cancer cells is $100 \%$ (8/8). And whether or cancerous adenomatous tissue lesions are present locally focal staining, and cancerous lesions focal dyeing range increased significantly. 98\% (83/85) of invasive adenocarcinoma expression of VEGF-C shows the diffuse type (60\%) and the point stove type (40\%). The research result also proves that the survival time of the positive VEGF-C patients is obviously lower than that of the negative VEGF-C patients. In colorectal cancer, the expression level of VEGF-C has become one of the decisive factors affecting the patient prognosis [63]. Holmqvist et $a l$. have found out that the lymphatic capillary vessel density surrounding the tumor tissues is also one of the dependent dangerous elements to determine the survival of colorectal cancer patients [64]. However, some studies show the expression of VEGF-C mRNA inside colorectal cancer has no connection with lymph node metastasis, but the expression of VEGF-D is significantly associated with pathological type of the colorectal cancer patients and lymph node metastasis and prognosis. Therefore, some people suspect that in the progress of colorectal cancer the in balanced expression of VEGF-C, VEGF-D and VEGFR-3 within human body induces the occurrence of lymphangiogenesis and promotes lymph node metastasis of tumor cancers but the specific molecular mechanisms are still unknown. The experiment by Miyazaki et al. has suggested that VEGF-C has a high expression in the colorectal cancer patients' serum after lymph node metastasis, and thus the detection of its expression density will be helpful for preoperative clinical stages [65]. The lymph node metastasis of tumor cells is 
a major metastasis pathway of breast cancer and one of important factors of patients' prognosis. In breast cancer patients, VEGF-C is expressed in $83.7 \%$ patients and the expression has significant correlation between lymph node metastasis $(p=0.0131$ ) [66]. Some studies about gallbladder carcinoma also demonstrate that 63\% patients have the positive expression of VEGF-C, which is associated with patients' regional lymph node metastasis and prognosis survival time, but no obvious correlation with capillary density level. Lymph node metastasis is one of the independent prognosis elements [67]. The study of Hashimoto et al. have also found out that in cervical cancer the expression level of VEGF-C mRNA is the only independent influential factor of pelvic lymph node metastasis [68].

Among the 186 gastric cancer tissue specimens, the positive and negative lymph node metastasis cases are 96 and 90 . The positive expression rate of VEGF-C is 54.83\% (102/186), where $\mathrm{N}(-)$ group is $34.44 \%$ (31/90) and $\mathrm{N}(+)$ is $73.9 \%(71 / 96)(p=0.001)$. The immunohistochemical staining of lymphatic vessels on the edge of the tumor show the positive expression of VEGFR-3 is about 33.33\% (62/186), where $\mathrm{N}(-)$ is $21.11 \%(19 / 90)$ and $\mathrm{N}(+)$ is $44.78 \%(43 / 96)(p=0.001)$ with statistical differences. The lymph node metastasis of positive expression of VEGF-C is about 68.93\% (71/103) and the negative expression lymph node metastasis rate is about 28.91\% (24/83), $p=0.001$; the positive expression lymph node metastasis rate is about $66.66 \%$ (42/63) and positive expression rate is about $43.09 \%(53 / 123), p=0.002$ with statistical differences. The result shows the expression of VEGF-C and VEGFR-3 is closely related to tumor lymph node metastasis. Interestingly, the expression rates of VEGF-C and VEGFR-3 are increased with the growth of clinical stages and the positive expression rate of VEGF-C has statistical differences among various clinical stages $(p<0.05)$, but the positive expression rates of VEGFR-3 among various clinical stages do not have statistical differences. Evaluating the microvessel density (MVD) through CD staining, there are no statistical differences between the positive and negative groups of lymph node. Through the VRGFR-3 staining of microlymphatics, assessing lymphatic vessel density (LVD), there are significant statistical differences between the positive and negative groups of lymph node; average LVD shows significant differences. This shows that gastric cancer lymph node metastasis is obviously related to the expression level of VEGF-C. In terms of lymph node metastasis, LVD is a more accurate index. As known to all, gastric cancer lymph node metastasis is one of the major elements of affecting prognosis. In this study, patients of the lymph node positive group only have $31 \%$ of five-year overall survival rate; the five-year overall survival rate for the negative group patients reaches $66 \%$ with significant statistical differences. The five-year overall survival rate of the negative expression of VEGF-C patients is about 59\%; the five-year overall survival rate of the positive expression patients is about $36 \%$ with statistical differences. The five-year overall survival rate of the negative expression of VEGFR-3 patients is about 43\%; the five-year overall survival rate of the positive expression patients is only about $31 \%$ also with statistical differences. A further stratified analysis has found out that among the positive expression of VEGF-C and VEGFR-3 patients the five-year overall survival rate is only $31 \%$ with statistical differences, indicating a poor prognosis. The logistic regression analysis has found out that the OR vales of VEGF-C and VEGFR-3 are both greater than 1 to show that they are dangerous elements for gastric cancer lymph node metastasis. The Cox regression analysis has found out the OR values of tumor invasion depth, lymph node metastasis, liver metastasis, intraoperative blood transfusion and the VEGF-C and VEGFR-3 expression are greater than 1 to show they are dangerous elements to reduce patients' survival time. The OR values of lymph node dissection and patients ages are smaller than 1 so that they are protective elements to increase patients' survival time. Based on the above experiments' results, it is believed that the expressions of VEGF-C and its specific receptor VEGFR-3 in gastric cancer are associated with lymph node metastasis. There is a poor prognosis for the patients when the expressions of VEGF-C and VEGFR-3 are positive. The expression of VEGF-C is one of the independent indexes to predict lymph node metastasis, which can be used as an independent element to affect the prognosis of the gastric cancer patients.

\section{Conclusion}

In summary, our data demonstrated that the expressions of VEGF-C, VEGFR-3 in cell plasma of gastric cancer tissue not only correlate with lymphatic vessel density and lymph node metastasis (LNM), but also are important factors which impacts prognosis of gastric cancer patients.

\section{Acknowledgements}

We thank the participants and their families for their kind cooperation, generosity and patience. 


\section{References}

[1] Jemal, A., Bray, F., Center, M.M., Ferlay, J., Ward, E. and Forman, D. (2011) Global Cancer Statistics. CA: A Cancer Journal for Clinicians, 61, 69-90. http://dx.doi.org/10.3322/caac.20107

[2] Ferlay, J., Soerjomataram, I.I., Dikshit, R., Eser, S., Mathers, C., Rebelo, M., Parkin, D.M., Forman, D.D. and Bray, F. (2014) Cancer Incidence and Mortality Worldwide: Sources, Methods and Major Patterns in GLOBOCAN 2012. International Journal of Cancer, Published Online. http://dx.doi.org/10.1002/ijc.29210

[3] Chen, W., Zheng, R., Zhang, S., Zhao, P., Li, G., Wu, L. and He, J. (2013) The Incidences and Mortalities of Major Cancers in China, 2009. Chinese Journal of Cancer Research, 32, 106-112. http://dx.doi.org/10.5732/cjc.013.10018

[4] Akagi, K., Ikeda, Y., Miyazaki, T., et al. (2000) Vascular Endothelial Growth Factor-C Expression in Human Colorectal Cancer Tissues. British Journal of Cancer, 83, 887-891. http://dx.doi.org/10.1054/bjoc.2000.1396

[5] Shayan, R., Achen, M.G. and Stacker, S.A. (2006) Lymphatic Vessels in Cancer Metastasis: Bridging the Gaps. Carcinogenesis, 27, 1729-1738. http://dx.doi.org/10.1093/carcin/bgl031

[6] Mumprecht, V. and Detmar, M. (2009) Lymphangiogenesis and Cancer Metastasis. Journal of Cellular and Molecular Medicine, 13, 1405-1416. http://dx.doi.org/10.1111/j.1582-4934.2009.00834.x

[7] Ferrara, N. (2001) Role of Vascular Endothelial Growth Factor in Regulation of Physiological Angiogenesis. American Journal of Physiology-Cell Physiology, 280, C1358-C1366.

[8] Karkkainen, M.J. and Petrova, T.V. (2000) Vascular Endothelial Growth Factor Receptors in the Regulation of Angiogenesis and Lymphangiogenesis. Oncogene, 19, 5598-5605. http://dx.doi.org/10.1038/sj.onc.1203855

[9] Yonemura, Y., Endo, Y., Fujita, H., Fushida, S., Ninomiya, I., Bandou, E., Taniguchi, K., Miwa, K., Ohoyama, S., Sugiyama, K. and Sasaki, T. (1999) Role of Vascular Endothelial Growth Factor C Expression in the Development of Lymph Node Metastasis in Gastric Cancer. Clinical Cancer Research, 5, 1823-1829.

[10] Yonemura, Y., Fushida, S., Bando, E., Kinoshita, K., Miwa, K., Endo, Y., Sugiyama, K., Partanen, T., Yamamoto, H. and Sasaki, T. (2001) Lymphangiogenesis and the Vascular Endothelial Growth Factor Receptor (VEGFR)-3 in Gastric Cancer. European Journal of Cancer, 37, 918-923. http://dx.doi.org/10.1016/S0959-8049(01)00015-6

[11] Karkkainen, M.J. and Alitalo, K. (2002) Lymphatic Endothelial Regulation, Lymphoedema, and Lymph Node Metastasis. Seminars in Cell \& Developmental Biology, 13, 9-18. http://dx.doi.org/10.1006/scdb.2001.0286

[12] De Asellius, G. (2008) Lacteibussivelacteisvenis Quarto Vasorum Mesaroicumgenere novo invente Gasp. Asellii Cremonensis Antomici Ticiensis Qua Sententiae Anatomicaemultae, nelperperamreceptaeillustrantur. Mediolani, Milan, 1627.

[13] David-Nathanson, S. (2003) Insights into the Mechanisms of Lymph Node Metastasis. Cancer, 98, 413-423. http://dx.doi.org/10.1002/cncr.11464

[14] Nobutsugu, A., Takashi, W., Kazufumi, S., et al. (2002) Risk Factors Predictive of Lymph Node Metastasis in Depressed Early Gastric Cancer. The American Journal of Surgery, 183, 168-172. http://dx.doi.org/10.1016/S0002-9610(01)00860-1

[15] Senger, D.R., Galli, S.J., Dvorak, A.M., et al. (1983) Tumor Cells Secrete a Vascular Permeability Factor That Promotes Accumulation of Ascites Fluid. Science, 219, 983-985. http://dx.doi.org/10.1126/science.6823562

[16] Ferrara, N. and Henzel, W.J. (1989) Pituitary Follicular Cells Secrete a Novel Heparin-Binding Growth Factor Specific for Vascular Endothelial Cells. Biochemical and Biophysical Research Communications, 161, 851-858. http://dx.doi.org/10.1016/0006-291X(89)92678-8

[17] Gospodarowicz, D. and Lau, K. (1989) Pituitary Follicular Cells Secrete both Vascular Endothelial Growth Factor and Follistatin. Biochemical and Biophysical Research Communications, 165, 292-298. http://dx.doi.org/10.1016/0006-291X(89)91068-1

[18] Ferrara, N., Gerber, H.-P. and LeCouter, J. (2003) The Biology of VEGF and Its Receptors. Nature Medicine, 9, 669676. http://dx.doi.org/10.1038/nm0603-669

[19] Lazăr, D., Tăban, S., Ardeleanu, C., Simionescu, C., Sporea, I., Cornianu, M. and Vernic, C. (2008) Immunohistochemical Expression of the Cyclooxygenase-2 (COX-2) in Gastric Cancer. The Correlations with the Tumor Angiogenesis and Patients Survival. Romanian Journal of Morphology and Embryology, 49, 371-379.

[20] Joukov, V., Pajusola, K., Kaipainen, A., Chilov, D., Lahtinen, I., Kukk, E., et al. (1996) A Novel Vascular Endothelial Growth Factor, VEGF-C, Is a Ligand for the Flt-4(VEGFR-3) and KDR(VEGFR-2) Receptor Tyrosine Kinases. The EMBO Journal, 15, 290-298.

[21] Lee, J., Gray, A., Yuan, J., et al. (1996) Vascular Endothelial Growth Factor-Related Protein: A Ligand and Specific Activator of the Tyrosine Kinase Receptor Flt4. Proceedings of the National Academy of Sciences of the United States of America, 93, 1988-1992. 
[22] Siegfried, G., Basak, A., Cromlish, J.A., et al. (2003) The Secretory Proprotein Convertases Furin, PC5, and PC7 Activate VEGF-C to Induce Tumorigenesis. Journal of Clinical Investigation, 111, 1723-1732. http://dx.doi.org/10.1172/JCI200317220

[23] Saharinen, P., Tammela, T., Karkkainen, M.J., et al. (2004) Lymphatic Vasculature: Development, Molecular Regulation and Role in Tumor Metastasis and Inflammation. Trends in Immunology, 25, 387-395. http://dx.doi.org/10.1016/j.it.2004.05.003

[24] Tang, R.F., Wang, S.X., Zhang, F.R., Peng, L., Wang, S.X., Xiao, Y. and Zhang, M. (2005) Interleukin-1alpha, 6 Regulate the Secretion of Vascular Endothelial Growth Factor A, C in Pancreatic Cancer. Hepatobiliary \& Pancreatic Diseases International, 4, 460-463.

[25] Pajusola, K., Aprelikova, O., Armstrong, E., Morris, S. and Alitalo, K. (1993) Two Human FLT4 Receptor Tyrosine Kinase Isoforms with Distinct Carboxy Terminal Tails Are Produced by Alternative Processing of Primary Transcripts. Oncogene, 8, 2931-2937.

[26] Lymboussaki, A., Partanen, T.A., Olofsson, B., et al. (1998) Expression of the Vascular Endothelial Growth Factor C Receptor VEGFR-3 in Lymphatic Endothelium of the Skin and in Vascular Tumors. The American Journal of Pathology, 153, 395-403. http://dx.doi.org/10.1016/S0002-9440(10)65583-6

[27] Clauss, M. (2000) Molecular Biology of the VEGF and the VEGF Receptor Family. Seminars in Thrombosis and Hemostasis, 26, 561-569. http://dx.doi.org/10.1055/s-2000-13213

[28] Reis-Filho, J.S. and Schmitt, F.C. (2003) Lymphangiogenesis in Tumors: What Do We Know? Microscopy Research and Technique, 60, 171-180. http://dx.doi.org/10.1002/jemt.10255

[29] Schmid-Schonbein, G.W. (1990) Microlymphatics and Lymph Flow. Physiological Reviews, 70, 987-1028.

[30] Alitalo, K. and Carmeliet, P. (2002) Molecular Mechanisms of Lymphangiogenesis in Health and Disease. Cancer Cell, 1, 219-227. http://dx.doi.org/10.1016/S1535-6108(02)00051-X

[31] Wigle, J.T. and Oliver, C. (1999) PROX-1 Function Is Required for the Development of the Murine Lymphatic System. Cell, 98, 769-778. http://dx.doi.org/10.1016/S0092-8674(00)81511-1

[32] Witte, M.H., Way, D.L., Witte, C.L., et al. (1997) Lymphangiogenesis: Mechanisms, Significance and Clinical Implications. Experientia Supplementum, 79, 65-112. http://dx.doi.org/10.1007/978-3-0348-9006-9_5

[33] Chang, L., Kaipainen, A. and Folkman, J. (2002) Lymphangiogenesis: New Mechanisms. Annals of the New York Academy of Sciences, 979, 111-119. http://dx.doi.org/10.1111/j.1749-6632.2002.tb04872.x

[34] Van-Netten, J.P., Cann, S.A. and van-der-Westhuizen, N.G. (1996) Angiogenesis and Tumor Growth. The New England Journal of Medicine, 334, 920-921. http://dx.doi.org/10.1056/NEJM199604043341413

[35] Marl, Y.H., Witte, M.J., Bernas, C.P., et al. (2001) Lymph Angiogenesis and Lymph Angiodysplasia: From Molecular to Clinical Lymphology. Microscopy Research and Technique, 55, 122-145. http://dx.doi.org/10.1002/jemt.1163

[36] de Waal, R.M., van Altena, M.C., Erhard, H., et al. (1997) Lack of Lymphangiogenesis in Human Primary Cutaneous Melanoma. Consequences for the Mechanism of Lymphatic Dissemination. The American Journal of Pathology, 150, 1951-1957.

[37] Kaipainen, A., Korhonen, J., Mustonen, T., van Hinsbergh, V.W., Fang, G.H., Dumont, D., et al. (1995) Expression of the Fms-Like Tyrosine Kinase 4 Gene Becomes Restricted to Lymphatic Endothelium during Development. Proceedings of the National Academy of Sciences of the United States of America, 92, 3566-3570.

[38] Karkkainen, M.J., Ferrel, R.E., Lawrence, E.C., et al. (2000) Missense Mutations Interfere with VEGFR-3 Signalling in Primary Lymphoedema. Nature Genet, 25, 153-159. http://dx.doi.org/10.1038/75997

[39] Jeltsch, M., Kaipainen, A., Joukov, V., et al. (1997) Hyperplasia of Lymphatic Vessels in VEGF-C Transgenic Mice. Science, 276, 1423-1425. http://dx.doi.org/10.1126/science.276.5317.1423

[40] Salven, P., Lymboussaki, A., Heikkila, P., et al. (1998) Vascular Endothelial Growth Factors VEGF-B and VEGF-C Are Expressed in Human Tumors. The American Journal of Pathology, 153, 103-108. http://dx.doi.org/10.1016/S0002-9440(10)65550-2

[41] Fielder, W., Graeven, U., Ergun, S., et al. (1997) Expression of FLT4 and Its Ligand VEGF-C in Acute Myeloid Leukemia. Leukemia, 11, 1234-1237. http://dx.doi.org/10.1038/sj.leu.2400722

[42] Fellmer, P.T., Sato, K., Tanaka, R., et al. (1999) Vascular Endothelial Growth Factor-C Gene Expression in Papillary and Follicular Thyroid Carcinomas. Surgery, 126, 1056-1061. http://dx.doi.org/10.1067/msy.2099.101432

[43] Tsurusaki, T., Kanda, S., Sakai, H., et al. (1999) Vascular Endothelial Growth Factor-C Expression in Human Prostatic Carcinoma and Its Relationship to Lymph Node Metastasis. British Journal of Cancer, 80, 309-313. http://dx.doi.org/10.1038/sj.bjc.6690356

[44] Andre, T., Kotelevets, L., Vaillant, J.C., et al. (2000) Vegf, Vegf-B, Vegf-C and Their Receptors KDR, FLT-1 and 
FLT-4 during the Neoplastic Progression of Human Colonic Mucosa. International Journal of Cancer, 86, 174-181. http://dx.doi.org/10.1002/(SICI)1097-0215(20000415)86:2<174::AID-IJC5>3.0.CO;2-E

[45] Achen, M.G., Jeltsch, M., Kukk, E., et al. (1998) Vascular Endothelial Growth Factor D (VEGF-D) Is a Ligand for the Tyrosine Kinases VEGF Receptor 2 (Flk1) and VEGF Receptor 3 (Flt4). Proceedings of the National Academy of Sciences of the United States of America, 95, 548-553. http://dx.doi.org/10.1073/pnas.95.2.548

[46] Stacker, S., Caesar, C., Baldwin, M.E., et al. (2001) VEGF-D Promotes the Metastatic Spread of Tumor Cells via the Lymphatics. Nature Medicine, 7, 186-191. http://dx.doi.org/10.1038/84635

[47] Yokoyama, Y., Charnock-Jones, D.S., Licence, D., et al. (2003) Expression of Vascular Endothelial Growth Factor (VEGF)-D and Its Receptor, VEGF Receptor 3, as a Prognostic Factor in Endometrial Carcinoma. Clinical Cancer Research, 9, 1361-1369.

[48] Skobe, M., Hawighorst, T., Jackson, D.G., et al. (2001) Induction of Tumor Lymphangiogenesis by VEGF-C Promotes Breast Cancer Metastasis. Nature Medicine, 7, 192-198. http://dx.doi.org/10.1038/84643

[49] Kajita, T., Ohta, Y., Kimura, K., et al. (2001) The Expression of Vascular Endothelial Growth Factor C and Its Receptor in Non Small Cell Lung Cancer. British Journal of Cancer, 85, 255-260. http://dx.doi.org/10.1054/bjoc.2001.1882

[50] Saharinen, P., Tammela, T., Karkkainen, M.J., et al. (2004) Lymphatic Vasculature: Development, Molecular Regulation and Role in Tumor Metastasis and Inflammation. Trends in Immunology, 25, 387-395. http://dx.doi.org/10.1016/j.it.2004.05.003

[51] Bierer, S., Herrmann, E., KÊpke, T., et al. (2008) Lymph Angiogenesis in Kidney Cancer: Expression of VEGF-C, VEGF-D and VEGFR-3 in Clear Cell and Papillary Renal Cell Carcinoma. Oncology Reports, 20, 721-725.

[52] Papontai, M., Sleeman, J.P. and Wilting, J. (2001) Interaction of Rat Tumor Cells with Blood Vessels and Lymphatics of the Avian Chorioallantoic Membrane. Microscopy Research and Technique, 55, 100-107.

[53] Padera, T.P., Kakambi, A., di Tomaso, E., et al. (2002) Lymphatic Metastasis in the Absence of Functional Intratumor Lymphatics. Science, 296, 1883-1886. http://dx.doi.org/10.1126/science.1071420

[54] Ueda, M., Terai, Y., Yamashita, Y., et al. (2002) Correlation between Vascular Endothelial Growth Factor C Expression and Invasion Phenotype in Cervical Carcinomas. International Journal of Cancer, 98, 335-343. http://dx.doi.org/10.1002/ijc.10193

[55] Maeda, K., Yashiro, M., Nishihara, T., et al. (2003) Correlation between Vascular Endothelial Growth Factor C Expression and Lymph Node Metastasis in Tl Carcinoma of the Colon and Rectum. Surgery Today, 33, 736-739. http://dx.doi.org/10.1007/s00595-003-2592-5

[56] Li, R., Younes, M., Wheeler, T.M., et al. (2004) Expression of Vascular Endothelial Growth Factor Receptor-3 (VEGFR-3) in Human Prostate. Prostate, 58, 193-199. http://dx.doi.org/10.1002/pros.10321

[57] Nathanson, S.D., Zarbo, R.J., Wachna, D.L., et al. (2000) Microvessels That Predict Axillary Lymph Node Metastases in Breast Cancer. Archives of Surgery, 135, 586-594. http://dx.doi.org/10.1001/archsurg.135.5.586

[58] Vatanabe, M., Ohga, T., et al. (2003) Vascular Endothelial Growth Factor C Expression Correlates with Lymphatic Involvement and Poor Prognosis in Patients with Esophageal Squamous Cell Carcinoma. Oncology Reports, 10, 1747 1751.

[59] Yonemura, Y., Fushida, S., Bando, E., Kinoshita, K., Miwa, K., Endo, Y., et al. (2001) Lymph Angiogenesis and the Vascular Endothelial Growth Factor Receptor (VEGFR)-3 in Gastric Cancer. European Journal of Cancer, 37, 918923.

[60] Duff, S.E., Li, C., Renehan, A.O., et al. (2003) Immunodetection and Molecular Forms of Plasma Vascular Endothelial Growth Factor-C. International Journal of Oncology, 22, 339-343.

[61] Da, M.X., Wu, X.T., Wan, G.J., et al. (2008) Expression of Cyclooxygenase-2 and Vascular Endothelial Growth Factor-C Correlates with Lymph Angiogenesis and Lymphatic Invasion in Human Gastric Cancer. Archives of Medical Research, 39, 92-99. http://dx.doi.org/10.1016/j.arcmed.2007.06.021

[62] Kazama, S., Kitayama, J., Watanabe, T. and Nagawa, H. (2004) Expression Pattern of Vascular Endothelial Growth Factor-C in Human Colorectal Normal Mucosa and Neoplastic Mucosa. Hepatogastroenterology, 51, $391-395$.

[63] Parr, C. and Jiang, W.G. (2003) Quantitative Analysis of Lymphangiogenic Markers in Human Colorectal Cancer. International Journal of Oncology, 23, 533-539.

[64] Holmqvist, A., Gao, J., Adell, G., et al. (2010) The Location of Lymphangi-Ogenesis Is an Independent Prognostic Factor in Rectal Cancers with or without Preoperative Radiotherapy. Annals of Oncology, 21, 512-517. http://dx.doi.org/10.1093/annonc/mdp486

[65] Miyazaki, T., Okada, N., Ishibashi, K., et al. (2008) Clinical Significance of Plasma Level of Vascular Endothelial Growth Factor C in Patients with Colorectal Cancer. Japanese Journal of Clinical Oncology, 38, 839-843. http://dx.doi.org/10.1093/jjco/hyn106 
[66] Nakao, K., Nakamura, M., Mori, I. and Kakudo, K. (2003) Clinicopathological Significance of Vascular Endothelial Growth Factor-C in Breast Carcinoma with Long-Term Follow-Up. Modern Pathology, 16, 309-314. http://dx.doi.org/10.1097/01.MP.0000062858.98295.9F

[67] Nakashima, T., Kondoh, S., Kitoh, H., et al. (2003) Vascular Endothelial Growth Factor-C Expression in Human Gallbladder Cancer and Its Relationship to Lymph Node Metastasis. International Journal of Molecular Medicine, 11, 33-39.

[68] Hashimoto, L., Kodama, J., Seki, N., et al. (2001) Vascular Endothelial Growth Factor-C Expression and Its Relationship to Pelvic Lymph Node Status in Invasive Cervical Cancer. British Journal of Cancer, 85, 93-97. http://dx.doi.org/10.1054/bjoc.2001.1846 
Scientific Research Publishing (SCIRP) is one of the largest Open Access journal publishers. It is currently publishing more than 200 open access, online, peer-reviewed journals covering a wide range of academic disciplines. SCIRP serves the worldwide academic communities and contributes to the progress and application of science with its publication.

Other selected journals from SCIRP are listed as below. Submit your manuscript to us via either submit@scirp.org or Online Submission Portal.
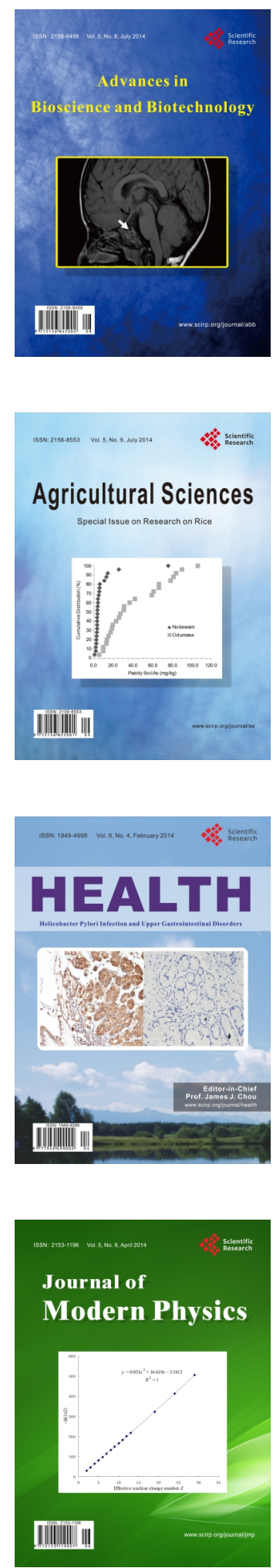
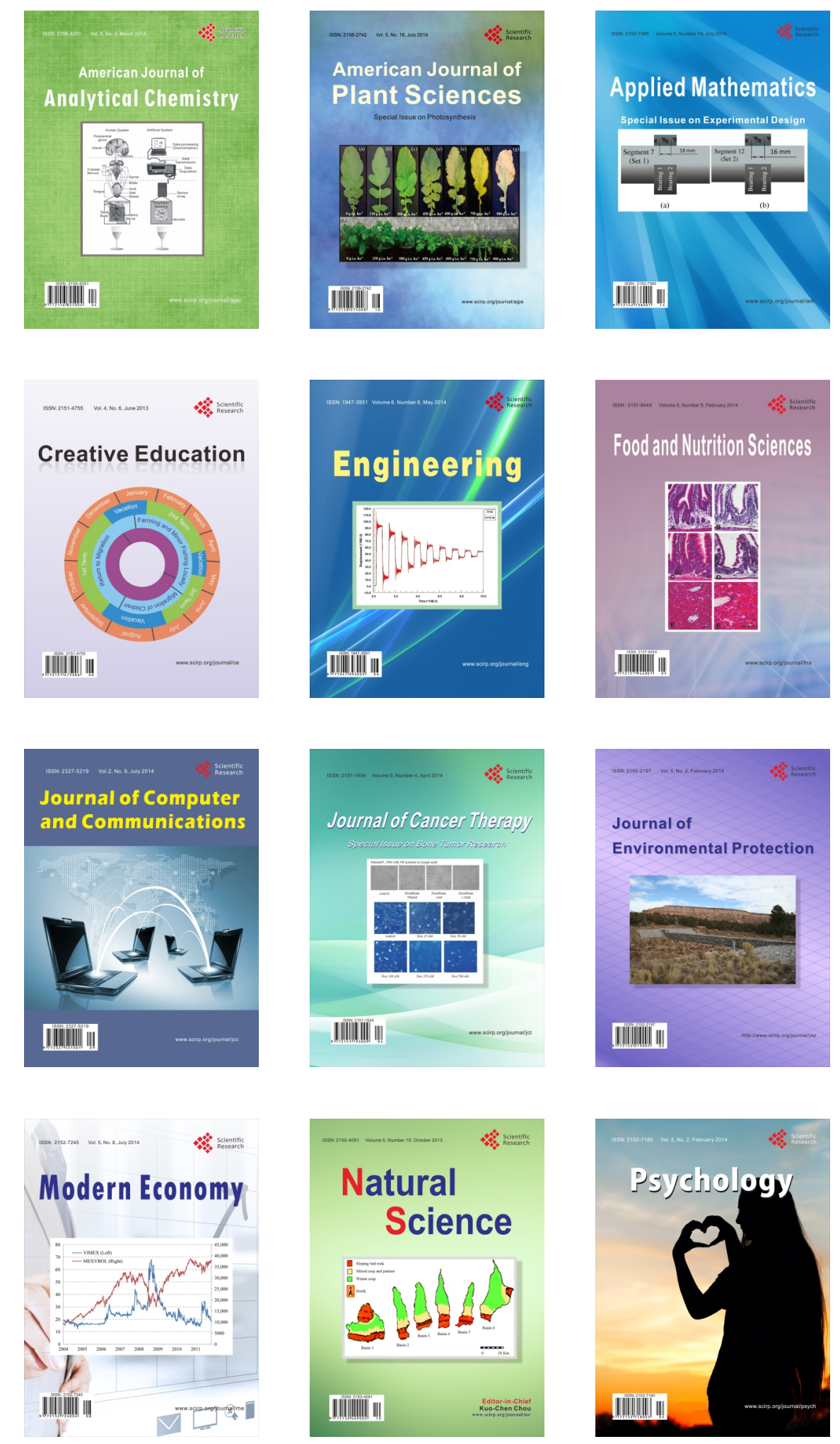